\title{
Generalization of Foreign Experience in the Career Guidance Center Work of Urfu
}

\author{
A.A. Polozov \\ Doctor of pedagogical sciences, Associate Professor, Institute of Physical Education, Sport and Youth Policy, \\ Ural Federal University (Ekaterinburg, Russia) \\ a.a.polozov@mail.ru
}

\begin{abstract}
The subject of the work was to improve the methodology of the career guidance center of the URFU (Yekaterinburg, Russia) by overcoming contradictions in the recommendations on the profiles of activities for people with different types of personality. An adequate recommendation is based on combination of the generalized opinion of experts $(12$ career centers at the US universities, authors of 8 books) on the profile of the applicant's activity (manager, agent, etc.) and 24 fields of activity. Due to this solution it was possible to evaluate each sphere for the applicant by saturation with suitable profiles. And it extremely increases his chances to realize the most significant project by the age of 39. The methodology was based on the typological concept of the personality structure from the personality type, the character type and the dominant type of intelligence. This concept in contrast with the five-factor model of the personality structure demonstrates a significant result of the work. About $70 \%$ of graduates of the Russian universities do not work on the received specialty. For 7 years the presented methodology of the vocational guidance center of the URFU (Yekaterinburg, Russia) was improved to the level at which these "lost" 70\% were detected at the testing stage before entering the university. The typological model defines a large field of variations $P T+C T+T I$ in which talent can be multidirectional. This makes the career center mission not always feasible. The center should have the ability to design a personalized project. In career centers at the US universities the applicant is recommended a variety of options where he can be useful. Thus, they shift the responsibility of the problem of choice to applicants' shoulders. The proposed methodology allows forming a project in which he will be most effective and competitive.
\end{abstract}

Keywords

Psychology;

profession;

applicant;

university

\section{Introduction}

In the 105 Russian universities 127.4 thousand students were studying in 1914 academic year, 2.8 million - in 1995, 6.5 million - in 2011. According to All-Russian center of learning social opinion data in 2012 only $56 \%$ of graduates work in their specialty in Russia. According to different mass media estimates $75-92 \%$ of graduates do not work in their specialty. In URFU $-70 \%$ of graduates. A. Fursenko, the former Minister of Education, gave the most $-92 \%$. So, about $70 \%$ of the budget money is not effectively spent on education.

To illustrate the problem we will show it on the example of the government of the Russian Federation of 2018. "Tatyana Golikova is perhaps the only pros because she is an economist by profession ("labor economics") and she headed the Accounting Chamber in the past. Vitaly Mutko supervising construction and regions is an engineer-mechanic of water transport on the first education and lawyer on the second (1999). Alexei Gordeev who 
oversees agriculture is a railroad engineer. Dmitry Patrushev, Minister of the same agriculture, is a manager and diplomat (Candidate Degree in the economy of research organizations). Maxim Akimov graduated from the History Institute of the Tsiolkovsky Pedagogical Institute, and now he oversees communications, transportation and "digitalization of the economy" as vice-premier. Dmitry Rogozin, a graduate of journalism, will head Roskosmos. Denis Manturov, the Minister of Industry and Trade, is a sociologist. Alexander Novak, the Minister of Energy, is a metallurgical engineer. Yevgeny Dietrich, Transport Minister, is an expert in applied mathematics. Vladimir Medinsky, the Minister of Culture, is an international journalist. Olga Vasilyeva, Minister of Education, is a directorchoirmaster on the first education. Mikhail Kotyukov supervising higher education is a financier». This example characterizes the situation better than other arguments. One person out of 12 in the government corresponds in his work to profile education.

The problem of professional orientation, choice of profession is connected with the ideas about the personality structure that changed with time. An example of a differential typological approach [2,4] can be considered the work of John Holland (1966). The basis was the division according to the types of personality (and environment): realistic, research, artistic-art, social, entrepreneurial, conventional. Career types, examples of professional behavior of successful work, life options (including labor activity), "pictures" of maximum productivity and its "downturns" in different age periods of life are typically distinguished in the structurally-behavioral approach. An example of the institutional approach is the concept of symbolic interactionism of Irwin Hoffmann (1959) where the professional behavior of people is regarded as their role in a scenario that combines the actions of individual characters in an integrated system. A person can be a seller and his client, a doctor and a patient, a boss and a secretary, etc. In the cognitive-motivational approach the process of professional self-determination is considered in the context of individual characteristics of person's prediction and decision-making. Career alternatives are compared by the subject of choice according to the value of the possible events associated with them.

\section{Review of Literature}

E.A. Klimov, the developer of the theory of the typological individual style of activity, Doctor of psychological science, Academician of the Academy of Pedagogical Sciences of the USSR (1930-2014) was the leading specialist in the Russian Federation. The starting points of the ISA concept were the following established facts:

1) Any person has qualities essential for success that are not educated.

2) There are several variants of adaptation to activity which are different in methods but equivalent in the final effect for any individual.

3) There are opportunities for overcoming weak abilities in most professions.

Subjective components of professional suitability are the following: civic qualities, attitudes toward the profession (propensities, interests, and preferences), health (physical and mental), individual and general abilities, skills (skills, knowledge, and experience). In Soviet times the personality was a small add-on to her civic position.

V.N. Kononova (from the Center for Testing and Development) identifies the following teaching profiles in the higher grades of the general education school: physics and mathematics, science, technology, social and economic, linguistic, humanitarian, artisticaesthetic, defense-sports, industrial-technological. Differential-diagnostic questionnaire of E.A. Klimov divides people into 5 categories: "man-nature", "man-technology", "man-man", 
"man-sign", "man-artistic image." A more modern approach can be found in the "Psychological foundations of vocational guidance. Classification of professions" lectures of Noskova O.G., the professor of Moscow State University (2014). It is supposed to divide the actions of the subject of labor according to the functions: 1-visual actions; 2 - auditory; 3 memory; 4 - imagination; 5 - logical (technical intelligence); 6 - logical (verbal intelligence); 7 - logical (social intelligence); 8 - communication; 9 - oral speech; 10 attention; 11 - will, self-regulation; 12 - motional.

Ismagilova F.S., Doctor of Psychology, professor, has written the dissertation on the subject "Professional experience of specialists and management of it ...." (2000). As the key factor she considers the specialist competitiveness which is provided by the following:

1) The integrated vision of the professional environment and yourself in it;

2) The level of competence that is adequate to the requirements of the employer,

3) The readiness to change this level in accordance with the requirements of the employer that are set up by the choice of a strategy for managing their professional resources. Therefore, a matrix of professional experience competitiveness (PEC) is built.

According to his education guidance (2003), Zeer V.F., Doctor of Psychology, recommends a 4-component personality structure consisting of the following:

1) Directivity (the system of dominant needs and motives)

2) Competence (awareness, erudition)

3) Important qualities (observation, memory, technical brainwork, spatial imagination, attentiveness, emotional stability, resolution, endurance, pliability, perseverance, purposefulness, discipline, self-control, etc).

4) Psychophysiological properties (neurotism, extraversion, reactivity, energy).

The personality directivity is identified with its motivation. Competencies are probability intellectual abilities that have been transformed into skills, etc. Since the 70's the so-called five-factor model of personality based on the psychometric approach is most widely used. It includes the following 5 factors presented in Table 1.

Table 1. Five-factor model of personality (B. Goldberg)

\begin{tabular}{|l|c|l|}
\hline Factor & & Positive pole Negative pole \\
\hline \multirow{2}{*}{ Extraversion } & + & Sociability, assertiveness, high activity \\
\cline { 2 - 3 } Goodwill & - & Calmness, passivity, restraint \\
\hline \multirow{2}{*}{ Conscientiousness } & + & Kindness, gullibility, warmth \\
\cline { 2 - 3 } & - & Hostility, selfishness, distrust \\
\cline { 2 - 3 } Emotional stability & - & Organizationality, thoroughness, reliability \\
\cline { 2 - 3 } & + & Carelessness, negligence, unreliability \\
\hline \multirow{2}{*}{ Intelligence } & - & Nervousness, irritability \\
\cline { 2 - 3 } & - & Nariosity, creativity \\
\hline
\end{tabular}

There were also techniques oriented at this model. In 2001, "Proforientator" computer diagnostic complex was created under the direction of Shmelev A.G., Doctor of Psychology, in Moscow. The center has more than 200 regional units throughout the territory of the Russian Federation. For the month about 500 people are tested. Testing runs for a 1 hour, conversation does for 30 minutes. The personality structure that is used in the test looks like this (Table 2): 
Table 2. "Proforientator" test structure by Shmelev A.G.

\begin{tabular}{|l|l|l|}
\hline $\begin{array}{l}\text { Structure of interests, } \\
\text { 84 statements }\end{array}$ & $\begin{array}{l}\text { Structure of the intellect, } \\
73 \text { questions }\end{array}$ & $\begin{array}{l}\text { Personality structure, } \\
50 \text { statements }\end{array}$ \\
\hline Е.А. Климов Дж. Холланд & & $\begin{array}{l}\text { Big Five personality } \\
\text { qualities }\end{array}$ \\
\hline Engineering & Vocabulary & Activity, initiative \\
\hline Science & Calculations & Consent - cooperation \\
\hline Art & Visual logic & Self-monitoring - planning \\
\hline Communication & Erudition & $\begin{array}{l}\text { Emotional stability } \\
\text { resistance to stress }\end{array}$ \\
\hline Business & Abstract Logic & \\
\hline Symbol & Attention & \\
\hline Nature & & \\
\hline Risk & & \\
\hline
\end{tabular}

As a result, the participant gets two diagrams.

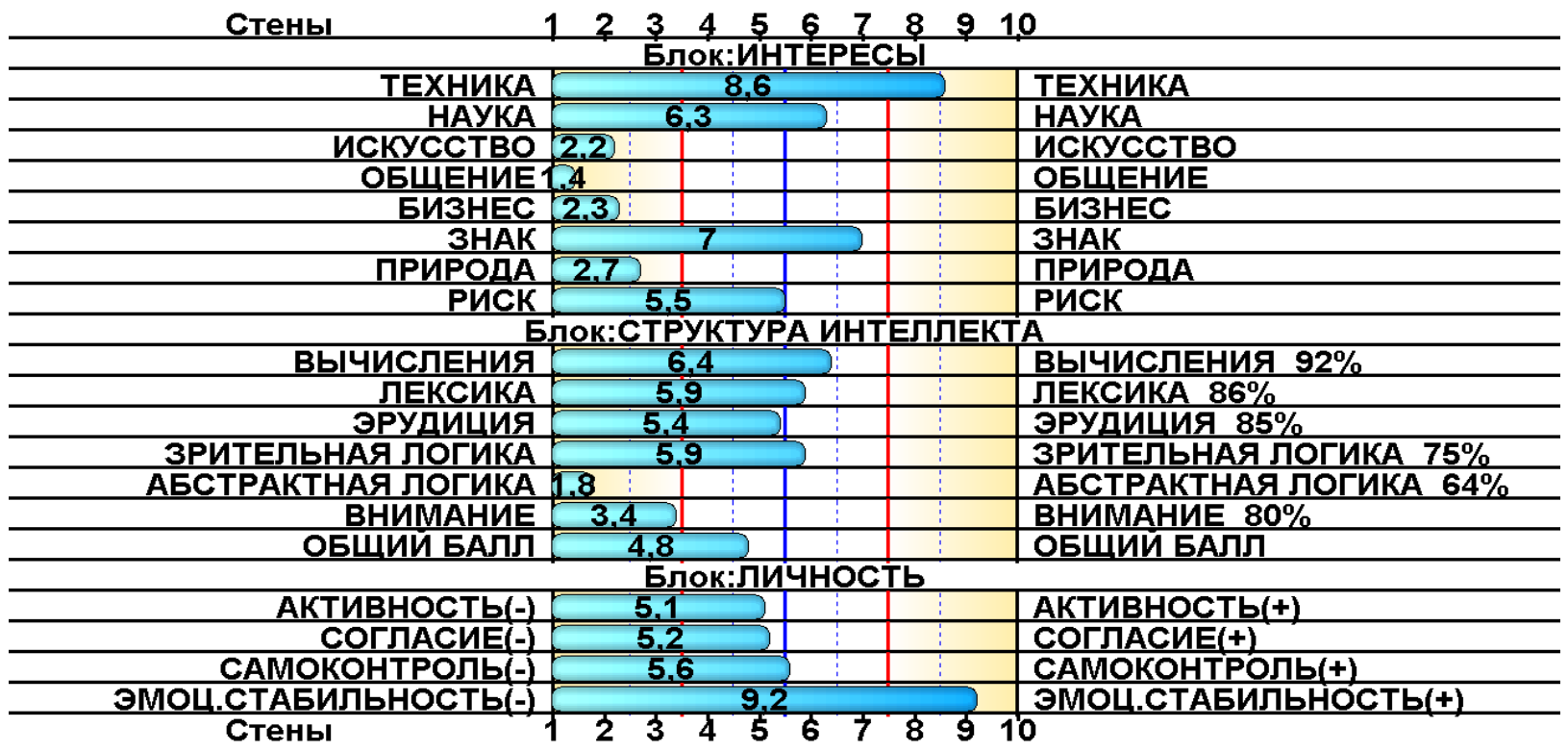

Figure 1. Sample of the diagnostic profile of the methods of A.G. Shmelev

After receiving the results, an experienced psychologist looks at them. Based on the result he must give advice where to go to learn.

Test of Shmelev A.G. is not career-oriented, does not give specialties at the university and shifts the interpretation of the results obtained to the person tested. It is necessary to choose from 8 directions rather than from 300 specialties of the university. In the course of research, the same individuals act both as test subjects and as experts. A.G. Shmelev believes that if the applicant entered the place where the Center directed, then this is the result of the work. However, we know that approximately $70 \%$ of graduates do not work in their specialty. Questions are formed as statements. This substitutes the conception of ability by interest. All questions suggest the context "I like to do ...". The goal of vocational guidance is not to find what the entrant might like, but to find out what he will be most effective in. 
The work of most career centers at the US universities is based on the Myers-Briggs personality typology. There is an MBTI test and, therefore, there is its criticism. In general, criticism is focused on the low validity of individual dichotomies. According to Abelskaya E.F. TF and EI are not in doubt, but SN and JP show "the conceptual similarity between $\mathrm{S}$ and J, N and P constructs". In other words, a correlation between the two dichotomies was found. The same feature is noted by McCrae R. (1985, 1989). Abelskaya E.F. made the research on students studying management, trade, etc. For the employees of trade, the JS priority is quite expected. If you need to find a correlation PS, then you need to do research on the army or police.

According to Myers and McCaulley (1993), the research of the type connections identified by MBTI and the number of their representatives in different professions did not reveal such pronounced links. This study only confirms that any enterprise is integrated into society and therefore should consist of diverse people.

The Military Research Institute conducting MBTI by order the US Army concluded that it was non-effective for career guidance (Druckman, D., 1991). The committee specially created by the US National Academy of Sciences also summarized the results of 20 MBTI validity studies and concluded that its T-F and S-N scales show low validity. On the basis of these results the test was found unusable for career guidance. The authors of this study for some reason did not think that:

1) In the military case, any creativity is excluded by the profession

2) There are such dichotomies that are not significant in general for the industry

3) There are others, significant factors (intellectual abilities, volitional, etc.) that have remained outside the MBTI and therefore do not allow making such categorical conclusions on the MBTI. The test cannot be responsible for other areas of the personality.

The typological approach supposes the presence of bright "types", that is, the bimodal distribution of answers on the dichotomous scale. While in studies the distribution of answers tends toward the normal with the center in equilibrium for all 4 binary features (intellectionfeeling, extraversion-introversion, etc.) Thus, a large number of people will be assigned to essentially different types if there is an insignificant difference in the values measured by the test. This situation also increases the probability of a measurement error (McCrae R. R., Costa P.T. 1989, Stricker, L, 1964). Let's take the conventional scale EI in the range from 0 to 100. The introvert with schizoid CT is taken for zero, extrovert with hysterical CT - for 100. We are sure to get a normal distribution with an inflection point of 50. There will be both: an introvert with hysterical CT and an extrovert with schizoid CT. This does not refute the presence of EI.

In the review of the Russian translation of the book by I. Myers-Briggs and P. Myers "MBTI: Definition of Types", A.G. Shmelev (2010) points out that the theory of the MyersBriggs typology contains the following "stretches" that were not subsequently confirmed when recruiting empirical data:

- None of the MBTI factors correlates with the level of person's mastering of moral and social behavior regulators, i.e. with criterion such as predisposition to corporate loyalty, which is important enough in the selection of personnel as opposed to the desire to steal the company, for example.

- People described as "pure" MBTI types are much less than "mixed" types. A typical situation is when according to answers a person with a probability of 0.6 belongs to one type, 0.5 - to another and 0.4 - to a third one, for example. Dropping information 
about the second and third possible types leads to coarsening and loss of accuracy of the scheme predictions.

- The theory of types denies the superiority of a parametric description over a typological description that contradicts the data accumulated in psychometry. The parametric description is basically an indication of the measured position of the human psyche in a multidimensional parameter space, and a typological description is just an indication of which region a person is on by some criteria that coarsens the scheme.

Arguments of A.G. Shmelev does not seem essential. He searches in MBTI tests for what they did not put there. In this case it is intellectual giftedness. Corporate loyalty is a secondary production concept which inexplicably became primary to the categories of psychology. Tests by the A.G. Shmelev do not contain the ability to altruism, hedonism, etc. Types become mixed because PT, CT and TI can in a certain sense contradict each other. For example, ESTP is usually decisive people. But the ESTP with depressive CT are inclined to provide an opportunity to decide for them. Is it possible to take the MBTI typology for an example of effective management of a scientific idea? How much research has been done on it.

Why has this problem not been solved for many years?

1) Psychologists cannot find a model of personality structure that would become the basis of the model of professional orientation

2) Disagreements on the structure of intelligence and the adequacy of tests.

3) Universities and schools are not responsible for where their graduate goes. They are responsible only for his level of preparation, but not for the validity of his choice.

4) Applicants have difficulties with testing because they know themselves badly. Incorrect self-identification in the tests does not approach the solution of the problem, but distances it.

5) Another part of the applicants want to make mistakes themselves, they not allow making a choice for them.

6) A huge number of untenable methods of career guidance. For example, the fingerprint testing methodology was officially recognized as a charlatan by the Russian Academy of Sciences in 2017.

7) The concept of a career and the best choice of the trajectory of motion are of an uncertain nature.

8) There are difficulties in proving the correctness of the choice. The result of the recommendation can be known in several decades. There are no generally accepted selection criteria. There is also methodological discrepancy of different approaches.

9) The desire of parents to recommend a child a convenient way for them to solve the problem.

10) There are no opportunities for the applicant to work a short term in the chosen specialty in the lower post.

11) The unwillingness of the scientific community to consolidate around a compromise problem solution, unreasonable inflation of this or that aspect of the problem.

12) Substitution of the decision of a trade choice problem by decisions of other problems: an opportunity to enter a specialty with low competition, convenience to get to places of study, to enter for the company with someone, etc. 
13) It is often recommended an industry where an applicant could work, rather than the place where he would be most effective.

\section{Research Method}

\subsection{The Method of Professional Orientation Test in the Theses:}

1) The methodology is based on the typological model of the personality structure and it is not aimed at what a person could do, but on what he will be most effective, competitive.

2) The person is estimated by his most famous, significant project which is expected to be realized by him as a performer at the age of 25 , and as a leader at 39 [9, 28].

3) In order to implement such a project, leadership is necessary at once for a number of competencies. Accordingly, the selection criterion is the branch of activity itself, which is the more preferable, the more the possible profiles of activity are in it.

4) The field of activity in the field of the priority project should correspond to the motivational hierarchy of the applicant.

5) An obligatory condition for the implementation of the author's mega-project is an effective business partner. Each of us has its advantages and disadvantages. Disadvantages should be closed by business partners. It is ideally, if one of the two partners is an innovator, and another is an expert.

6) The giftedness of any person is unconventional and it requires the creation of a local project. However, it is initially necessary to review all the expected projects involving innovative technologies in the chosen field.

7) The way to the mega-project will consist of local projects. It is necessary to set a task that exceeds the available possibilities for its solution in each of those local projects.

Let us explain some of the poins of the methodology and identify the problem of research.

The methodology is based on the typological model of the personality structure . The personality consists of three segments: the sphere of focus of interests, "will and feelings," the associative-intellectual sphere (K. Leonhard, 1988). The author suggested to "place" known psychotypes in each of these segments. These are types of personality (PT), character (CT) and a number of types of intelligence (TI), some of which can dominate. CT includes schizoid, paranoid, narcissistic, psychopathic, compulsive, hysterical, depressive, and masochistic. TI by G. Gardner are the following: linguistic, analytical, spatial, musical, bodily-kinesthetic, interpersonal, and intrapersonal. We usually add tests for abstract logic and concentration of attention . The present "Big Five" is absorbed by the typological model.

Types of character limit the field for choice to a greater extent. For example, people with schizoid CT are not able to work with a high intensity of communication. People with narcissistic CT look for an administrative work. Types of personality and character simply screen out about $85 \%$ of options, but the further choice remains for intellectual giftedness. We give simplified examples. To work as a design engineer, for example, you need two types of intelligence - spatial and analytical. Another example, a girl with CT Compulsive ESFJ, with the dominance of spatial and analytical intelligence, can choose the management of the development business. EF and compulsive CT will allow her to communicate with a variety of clients for the sale of real property. SJ will allow her to qualitatively execute the transaction. Spatial intelligent and understanding the foundations of construction give her an 
understanding of the structure of the object being sold. In this case, she will win any competition.

As an example, let us cite the outstanding director of comedy films Eldar Ryazanov. His formula is PT ENFP CT Schizoid TI Linguistic. He was not only a director. He is the author of the script, the poet, the actor, the leader of the film panorama, etc. E. Braginsky was his business partner - co-author of all scripts for films. The popularity of his films was growing. These and other aspects led to a large number of masterpieces created by him.

The authors [29] obtained a graph of the age of scientific discoveries of Nobel laureates. It turned out that it is normally distributed around the age of 39 . The authors also made a similar study in the field of sports with the same result. The person is estimated by his most famous, significant project. The expected age of this project is 39 years old. It is important to find some prototype of the future project and to scale it step by step.

The work algorithm is built on examples of the achievements of people with a similar configuration of personality: the type of personality, character and the dominant type of intelligence. At our university we asked to pass the testing of the most famous graduates with their achievements and then the test results formed recommendations for entrants with a similar typological structure. However, the idea of the PT+CT+TI personality structure provides such a wide field of options that it is not possible to exhaust one sample. Therefore, most of the recommendations we received after processing the recommendations of career centers at American universities and well-known books on the personality typology.

The author conducted a study of the connection between motivation and PT, CT, the age of achievements in sports.

\subsection{Experimental Part}

People who completed their studies at the $4^{\text {th }}$ course were tested and answered the question about the future plans 2 months before the diploma. Testing was conducted in different education areas for 7 years. Summarized statistics give us $70 \%$ of graduates who do not plan to work in their specialty. The total number of respondents was 390 people.

Another quiz which also lasted for a long period was conducted among the most famous graduates of URFU. Due to these 120 people who passed the test and filled out the questionnaire it was possible to form the outlines of the methodology. There are 3 out of 10 questions when over $85 \%$ of the respondents gave solidary answers:

1) All respondents do not find difficulty in answering the question about the most significant achievement. It is an achievement that is considered to be their goal, and not a position, status, etc.

2) The majority of respondents had several necessary competences where their level was higher than that of their colleagues according to their own assessment. Respondents did not initially plan the most significant project. This came about as a "confluence of circumstances."

3) The respondents agree that until a certain age they create a reputation for themselves and after that it already works for them.

Subsequent studies have made it possible to formulate the methodology of the vocational guidance center of the URFU. However, many difficulties arose on the way to its realization.

The research problem is overcoming contradictions in the recommendations of American career centers and authors of books on professions for various PT. The local task 
was to form the branches with the greatest degree of specific dichotomies from such generalized opinions.

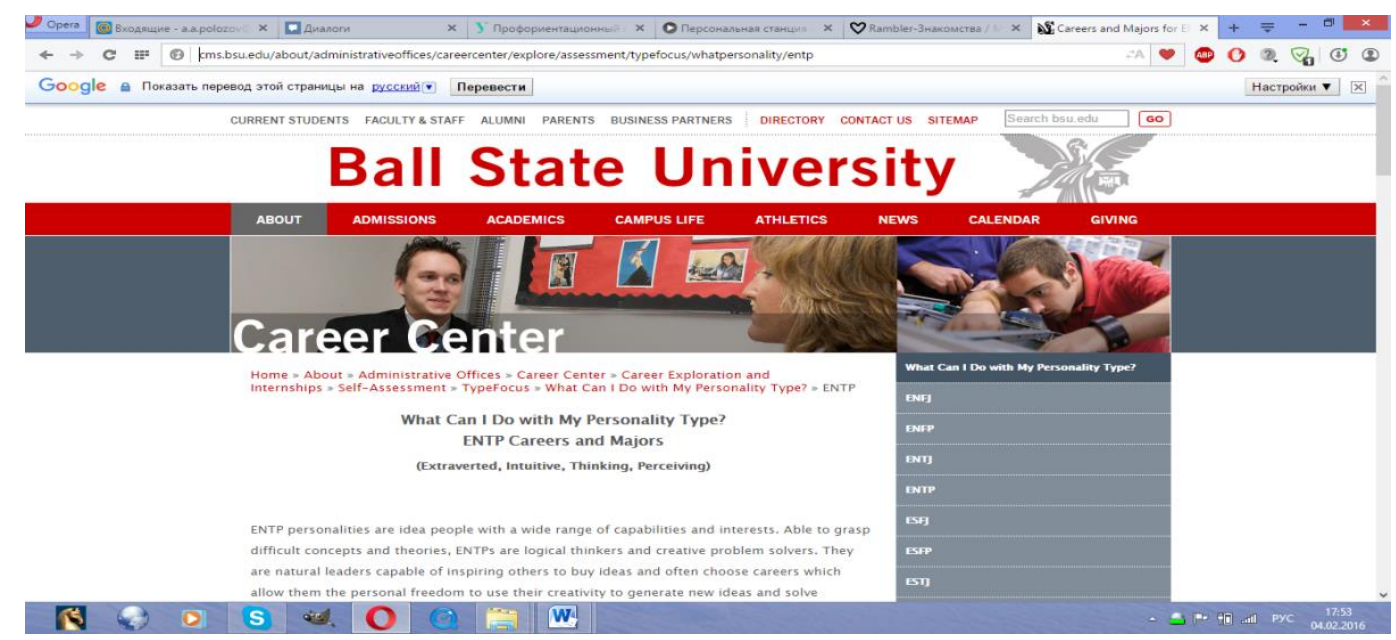

Figure 2. The US career center

According to the generalized data of 12 career centers at US universities and 8 books, a complete list of activity profiles is formed. It turned out that from 12 different sources people with 9 different PT claimed for a nutritionist vacancy, for example.

It was necessary to collect all the information and generalize them. In this case, many similar profiles have different names, for example, an actor and an artist. After the unification of the names there remained 588 vacancies and there were about 2.9 different PT variants for each of them. Each of the PT variants had an unequal specific gravity with other variants. One option was given greater preference and they were called more often.

There was an assumption that such a variation in the choice may be related to the industry factor. Therefore, it is necessary to identify the sectors in which the priority of dichotomies is viewed - the twofold and more superiority of expert opinions in pairs $\mathrm{J} / \mathrm{P}, \mathrm{E} / \mathrm{I}$, $\mathrm{S} / \mathrm{N}, \mathrm{T} / \mathrm{F}$. Such ratio in terms of pairs will be conditionally called the industry coefficient for this or that dichotomy. This problem was solved successively in several steps. It was not taken into account posts where a university education was unrequired. As a result, it was possible to sort out opinions on 25 different profiles (Table 3).

Table 3. Correlations of various dichotomies of authors [10-19, 22-27, 30] in various fields of activity

\begin{tabular}{|c|l|c|c|c|c|c|c|c|c|}
\hline & Field of activity & J & R & E & I & S & N & T & F \\
\hline 1 & Power, social sphere, society, politics, ecology & 28 & 18 & 31 & 13 & 22 & 33 & 22 & 28 \\
\hline 2 & Energy (electricity, heat, new sources) & 14 & 5 & 3 & 14 & 14 & 7 & 26 & 0 \\
\hline 3 & Oil and gas, mining, geology & 3 & 6 & 3 & 3 & 8 & 5 & 13 & 0 \\
\hline 4 & Banks, finance, securities, stock exchange & 26 & 14 & 22 & 23 & 28 & 22 & 46 & 9 \\
\hline 5 & Medicine, pharmaceutics, health & 29 & 28 & 17 & 36 & 34 & 25 & 19 & 33 \\
\hline 6 & Coordination, dispatching, logistics & 22 & 28 & 37 & 10 & 34 & 21 & 27 & 21 \\
\hline 7 & Personnel, psychology, sociology & 33 & 19 & 22 & 26 & 15 & 39 & 9 & 45 \\
\hline & $\begin{array}{l}\text { Technology, chemistry, physics of composites, } \\
\text { nanomaterials, metallurgy }\end{array}$ & 12 & 11 & 10 & 12 & 12 & 15 & 30 & 1 \\
\hline
\end{tabular}




\begin{tabular}{|c|l|c|c|c|c|c|c|c|c|}
\hline 9 & $\begin{array}{l}\text { Space, aviation, transport, auto, communications, } \\
\text { telecommunications }\end{array}$ & 6 & 23 & 10 & 12 & 28 & 10 & 27 & 2 \\
\hline 10 & $\begin{array}{l}\text { Mechanical engineering, instrument making, } \\
\text { electronics, mechanics }\end{array}$ & 22 & 11 & 9 & 20 & 28 & 10 & 43 & 6 \\
\hline 11 & Construction, real property, design, hydrology & 5 & 3 & 6 & 3 & 7 & 4 & 15 & 1 \\
\hline 12 & $\begin{array}{l}\text { Science, basic research, chemistry, physics, } \\
\text { mathematics }\end{array}$ & 16 & 22 & 11 & 23 & 7 & 31 & 35 & 4 \\
\hline 13 & Education, career guidance & 18 & 12 & 10 & 23 & 14 & 17 & 13 & 18 \\
\hline 14 & IT, Internet, programmer-developer & 23 & 31 & 12 & 47 & 22 & 38 & 56 & 13 \\
\hline 15 & Engineer-designer of DNA, biology, biotechnology & 11 & 12 & 2 & 26 & 8 & 24 & 22 & 7 \\
\hline 16 & $\begin{array}{l}\text { Public relations, advertising, brand, trade, PR, } \\
\text { communication }\end{array}$ & 18 & 32 & 46 & 9 & 23 & 23 & 17 & 43 \\
\hline 17 & Sport, recreation, tourism & 4 & 16 & 17 & 10 & 19 & 5 & 8 & 18 \\
\hline 18 & $\begin{array}{l}\text { Service, catering, organization of celebrations, } \\
\text { event management, manicure }\end{array}$ & 15 & 22 & 24 & 9 & 24 & 10 & 4 & 29 \\
\hline 19 & $\begin{array}{l}\text { Journalist, TV broadcast, advertising, polygraphy, } \\
\text { linguistics }\end{array}$ & 20 & 18 & 26 & 18 & 9 & 33 & 14 & 27 \\
\hline 20 & Architecture, design, artists, aesthetics, design & 11 & 27 & 5 & 31 & 12 & 23 & 19 & 17 \\
\hline 21 & $\begin{array}{l}\text { Art, artist, scriptwriter, musician, director, culture, } \\
\text { writer }\end{array}$ & 10 & 45 & 24 & 25 & 20 & 32 & 14 & 35 \\
\hline 22 & $\begin{array}{l}\text { Security, taxes, insurance, jurisprudence, attorney, } \\
\text { MES }\end{array}$ & 15 & 11 & 13 & 11 & 20 & 9 & 16 & 5 \\
\hline 23 & $\begin{array}{l}\text { Philosophy, theology, history, anthropologists, } \\
\text { schooling }\end{array}$ & 54 & 26 & 32 & 46 & 62 & 29 & 61 & 16 \\
\hline 24 & Agriculture, forestry & 5 & 6 & 0 & 6 & 8 & 3 & 7 & 2 \\
\hline
\end{tabular}

As you can see from Table 3, a number of areas of activity initially involve the work of a rather small number of PT in them. This conclusion explains to us the reason for the difference in opinions of the authors [10-19, 22-27, 30] in the profiles of PT.

The next step is to do a similar generalization no longer by industry, but by activity profiles and then synthesize PT formulas for managers, engineers, etc. for each industry. The criterion is the same - a minimum twofold superiority in the number of expert opinions in pairs $\mathrm{J} / \mathrm{P}, \mathrm{E} / \mathrm{I}, \mathrm{S} / \mathrm{N}, \mathrm{T} / \mathrm{F}$, which is marked by the number 1 in Table 4 . These correlations will be conditionally called the profile coefficient for each of the dichotomies. From a fairly large data sorting we learned that the manager is an extrovert and the teacher at school is F. Let's give only a part of the results.

Table 4. Correlations of various dichotomies of authors according to the posts regardless of the field of activity

\begin{tabular}{|c|l|c|c|c|c|c|c|c|c|c|c|c|c|c|c|c|c|}
\hline & & J & R & E & I & S & N & T & F & J & R & E & I & S & N & T & F \\
\hline 337 & Manager & & & 1 & & & & & & 183 & 154 & 226 & 111 & 163 & 174 & 169 & 168 \\
\hline 145 & Engineer & & & & & & & 1 & & 87 & 58 & 56 & 89 & 72 & 73 & 140 & 5 \\
\hline 102 & Consultant & & & & & & 1 & & 1 & 56 & 46 & 62 & 40 & 19 & 83 & 24 & 78 \\
\hline 100 & Coach & & 1 & 1 & & 1 & & & & 32 & 68 & 68 & 32 & 69 & 31 & 36 & 64 \\
\hline 98 & Analyst & & & & & & & 1 & & 62 & 36 & 41 & 57 & 34 & 64 & 87 & 11 \\
\hline 87 & Director & 1 & & 1 & & & & & & 68 & 19 & 70 & 17 & 43 & 44 & 46 & 41 \\
\hline 79 & Therapist & & & & & & & & 1 & 32 & 47 & 36 & 43 & 46 & 33 & 10 & 69 \\
\hline
\end{tabular}




\begin{tabular}{|c|c|c|c|c|c|c|c|c|c|c|c|c|c|c|c|c|c|}
\hline 77 & Administrator & 1 & & & & & & 1 & & 59 & 18 & 41 & 36 & 37 & 40 & 55 & 22 \\
\hline 71 & Designer & & 1 & & 1 & & & & 1 & 23 & 48 & 23 & 48 & 29 & 42 & 18 & 53 \\
\hline 69 & Doctor & & & & & 1 & & & & 34 & 35 & 30 & 39 & 48 & 21 & 25 & 44 \\
\hline 66 & Teacher & & & & & & & & 1 & 33 & 33 & 32 & 34 & 27 & 39 & 4 & 62 \\
\hline 65 & Employee & & & & & 1 & & & 1 & 30 & 35 & 36 & 29 & 46 & 19 & 14 & 51 \\
\hline 55 & $\begin{array}{l}\text { Social } \\
\text { Worker }\end{array}$ & & & & & & & & 1 & 27 & 28 & 24 & 31 & 24 & 31 & 0 & 55 \\
\hline 54 & Artist & & 1 & & & & & & 1 & 16 & 38 & 24 & 30 & 26 & 28 & 10 & 44 \\
\hline 51 & Psychologist & & & & & & 1 & & & 24 & 27 & 23 & 28 & 7 & 44 & 21 & 30 \\
\hline 49 & Journalist & & & & & & 1 & & & 18 & 31 & 32 & 17 & 8 & 41 & 27 & 22 \\
\hline 47 & Technician & & & & 1 & 1 & & & & 23 & 24 & 7 & 40 & 35 & 12 & 29 & 18 \\
\hline 45 & Interrogator & & & & & & & 1 & & 18 & 27 & 23 & 22 & 27 & 18 & 36 & 9 \\
\hline 44 & Mediator & & & 1 & & & & & 1 & 16 & 28 & 36 & 8 & 15 & 29 & 8 & 36 \\
\hline 44 & Scientist & & & & 1 & & 1 & 1 & & 22 & 22 & 14 & 30 & 10 & 34 & 32 & 12 \\
\hline 43 & Planner & & & 1 & & & 1 & & & 17 & 26 & 32 & 11 & 12 & 31 & 17 & 26 \\
\hline 42 & $\begin{array}{l}\text { Programmer- } \\
\text { developer }\end{array}$ & & & & & & 1 & 1 & & 19 & 23 & 15 & 27 & 9 & 33 & 36 & 6 \\
\hline 41 & Lawyer & & & & & & 1 & 1 & & 24 & 17 & 27 & 14 & 9 & 32 & 36 & 5 \\
\hline 35 & Writer & & & & & & 1 & & & 17 & 18 & 14 & 21 & 1 & 34 & 17 & 18 \\
\hline 34 & Pharmacist & & & & 1 & 1 & & & & 22 & 12 & 11 & 23 & 26 & 8 & 22 & 12 \\
\hline 34 & Photographer & & 1 & & & & & 1 & & 8 & 26 & 19 & 15 & 14 & 20 & 23 & 11 \\
\hline 33 & Nutritionist & & & & & & & & 1 & 17 & 16 & 16 & 17 & 15 & 18 & 0 & 33 \\
\hline 32 & Policeman & & & & & 1 & & & & 11 & 21 & 21 & 11 & 30 & 2 & 20 & 12 \\
\hline 30 & Mechanic & & 1 & & 1 & 1 & & 1 & & 8 & 22 & 9 & 21 & 25 & 5 & 27 & 3 \\
\hline 30 & Auditor & 1 & & & & 1 & & 1 & & 25 & 5 & 11 & 19 & 22 & 8 & 26 & 4 \\
\hline 29 & Lecturer & 1 & & & & & & 1 & & 22 & 7 & 15 & 14 & 16 & 13 & 20 & 9 \\
\hline 28 & Actor & & 1 & 1 & & & & & & 7 & 21 & 24 & 4 & 13 & 15 & 12 & 16 \\
\hline 28 & Dentist & 1 & & & & 1 & & & & 22 & 6 & 13 & 15 & 23 & 5 & 16 & 12 \\
\hline 28 & Musician & & 1 & & & & & & 1 & 8 & 20 & 11 & 17 & 12 & 16 & 9 & 19 \\
\hline 28 & Pilot & & & & & 1 & & 1 & & 11 & 17 & 12 & 16 & 24 & 4 & 25 & 3 \\
\hline 27 & Agent & & & 1 & & & & & 1 & 12 & 15 & 21 & 6 & 14 & 13 & 6 & 21 \\
\hline
\end{tabular}

Для каждой пары J/P, E/I, S/N, T/F условие выделения определялось как:

The next stage is the necessity to add typical positions in each of the 24 selected industries (manager, logistics, economist, etc.). This gap must be filled for all branches rather than to be represented selectively. This is a standard set of posts for each industry which is added to the existing profiles of activities in the industry. This led to a significant increase in the total number of PT profiles from 588 to 1,500. The final step was to determine the significance of dichotomies for each of them. For each pair J/P, E/I, S/N, T/F the allocation condition was defined as:

Profile coefficient $\times$ industry coefficient $=>2$

The selected values were marked by the number 1 . Here is an example of typical positions of a state enterprise (Table 5). 
Table 5. Significant dichotomies for typical state enterprise posts

\begin{tabular}{|l|l|l|l|l|l|l|l|l|}
\hline Director of the state enterprise & 1 & & 1 & & & & \\
\hline The administrator of the state enterprise & 1 & & 1 & & & & 1 & \\
\hline Manager of the state enterprise & 1 & & 1 & & & & & \\
\hline Marketer of the state enterprise & & & 1 & & & 1 & & \\
\hline Consultant of the state enterprise & 1 & & 1 & & & 1 & & 1 \\
\hline The agent of the state enterprise & & & 1 & & & & & 1 \\
\hline Economist of the state enterprise & 1 & & & 1 & & 1 & 1 & \\
\hline Mediator of the state enterprise & & & 1 & & & 1 & & 1 \\
\hline Consulting of state enterprises & 1 & & 1 & & & 1 & 1 & \\
\hline Coordinator of the state enterprise & & & 1 & & 1 & & & 1 \\
\hline Copywriter of the state enterprise & & 1 & 1 & & & 1 & 1 & \\
\hline Inspector of the state enterprise & 1 & & 1 & & 1 & & 1 & \\
\hline Auditor of the state enterprise & 1 & & & & 1 & & 1 & \\
\hline Accountant of the state enterprise & 1 & & & & 1 & & & \\
\hline The investor of the state enterprise & & 1 & 1 & & & 1 & 1 & \\
\hline Analyst of the state enterprise & 1 & & 1 & & & 1 & 1 & \\
\hline Planner of the state enterprise & & & 1 & & & 1 & & 1 \\
\hline Logist of the state enterprise & 1 & & 1 & & & & 1 & \\
\hline
\end{tabular}

IV. Result and Discussion

We left the many-voiced authors to the most balanced decision in the process of such work. Thus, all the data obtained was filtered and generalized. There were specific and nonspecific profiles in each of the 24 spheres of activity. The specific profiles have undergone a simple procedure for identifying significant dichotomies in a combination of opinions. The nonspecific profiles went through a more complicated procedure of combining universal profiles with the specific field of activity.

As a result of this work 1,500 variants of the activity profile were obtained. At the university the closest specialty was selected for each of them in accordance with the list of such specialties in Russia. After determining the applicant's PT+CT the list is reduced about up to $150-350$ options.

An important result of this work was the identification of activity profiles adapted to the specifics of the industry. This allows us to find suitable profiles for each PT+CT combination. The next step was the allocation for each profile of the most significant types of intelligence (TI). For example, it is analytical for an accountant, intrapersonal - for the writer, abstract logic - for the scientist. As a rule 1-3 of TI were allocated. Evaluation of the TI test was to compare the test for this applicant with the average statistical answer. Such an answer corresponded to 2.5 points on a 5-point scale. For each test, the average density of answers was calculated in order to correctly correlate the number of correct answers into points. As a result, for each profile of activity we obtained an average rating of profile intellectual abilities on a 5-point scale. The sum of such ratings for suitable profiles for a given applicant formed for him the final importance of the industry. The identification of such an industry is very important in that by getting into the right industry the applicant will independently find his 
own priority project for him. The significance of this factor is estimated at $40 \%$ of the total assessment. The significance of the activity profile itself was also estimated at $40 \%$.

In addition, the expected hierarchy of motives was formulated for each of the 1,500 profiles. In testing the applicant passes a motivation test in which his own hierarchy of motives is obtained. It is needless to expect that a person with a low level of "aesthetic" motive significance will choose the profile of the designer's activity.

An important problem is a low percentage of people with adequate answers during testing. There are about 50\%. This can be written about endlessly. All introverts with depressive CT consider themselves extroverts, and all extroverts with schizoid CT introverts. People with psychopathic CT cannot be tested themselves without help at all. Girls often choose F, and boys - T. Well-developed intelligence can "turn" F into T. Any compulsive $\mathrm{R}$ becomes $\mathrm{J}$, and $\mathrm{N}$ turns into $\mathrm{S}$. Motivation can be induced by parents. This is especially true for depressive CT. People with schizoid CT have 2-3 very narrowly specific interests and our opinion suggesting a way out of this framework simply will not make any difference. Exciting experiences are necessary for hysterical CT. People with high concentration of attention look older of the same age. The complexity of the personality structure leads to a low percentage of adequate testing. A child usually finds it difficult to answer questions that no one previously asked him. However, if you give him time to think and re-test, then the answers of the children are much more accurate. Therefore, testing is repeated in a month and in case of inconsistency of results is carried out for the third time.

\section{Conclusion}

1) The methodology of the vocational guidance center of URFU (Ekaterinburg, Russia) is presented in the work:

- The methodology is based on the typological model of the personality structure.

- It focuses on a significant project at the age of 39.

- The industry with the largest number of job profiles is selected.

- Conformity of motivational hierarchy of the applicant to the work.

- An effective business partner

- It is necessary to create a project for non-standard talent

- In each local project you must set tasks above the level.

About $70 \%$ of graduates of universities of the Russian Federation do not work on the received specialty. For 7 years the presented methodology of the vocational guidance center of the URFU (Yekaterinburg, Russia) was improved to the level at which these "lost" $70 \%$ were detected at the testing stage before entering the university.

2) The type of personality from Myers-Briggs is responsible for the direction of the interests of the individual and causes the greatest debate. The work was carried out to generalize different points of view resulting in a list of 1,500 activity profiles for 24 different spheres. Consolidation of points of view occurred with a double or more superiority of one of the alternatives over the other within the dichotomy. The methodology of the URFU center and the US career centers can be schematically written as PT+CT+TI $>$ TI. This approach allows us to distinguish not just the possible field of the applicant activity, but what he is most effective in. There is an example of a similar and more than successful person with impressive achievements for many variants of combining PT+CT+TI of an applicant.

3) The methodology eliminated unsuitable profiles for the given PT+CT combination. The remaining ones used the results of specialized intellectual tests. According to them the list 
was ranked. Another aspect of the technique was the capacity of each of the 24 spheres for a person with this $\mathrm{PT}+\mathrm{CT}$ combination - the number of acceptable activity profiles. It allows people to maneuver inside the industry when choosing a field of activity, and if there is a necessary number of competencies to lead a particular project.

\section{References}

Abelskaya, E.F. Typological study of the mental structure of the personality: the author's abstract. dis. ... cand. psychol. Sciences: 19.00.01

Anastasi A. Psychological testing. In 2 volumes / Ed. K.M. Gurevich, V.I. Lubovsky. M., 1982

Bykov D. The government is non-business. The interlocutor. May 2018

Zeer E.F. Psychology of professions: A manual for university students. $-2^{\text {nd }}$ ed., - Moscow: Academic Project; Ekaterinburg: the Business book, 2003. - 336 p.

Ivanova O.N., Odintsova V.V. Complex of testing "Professional orientation": psychometric and pragmatic properties of the test // Psychological diagnostics. 2006. No 2. - p. 4169.

Klimov E.A. How to choose a profession? -M., 1984; $2^{\text {nd }}$ ed. M., 1990.

A.A. Polozov and S. Skorykh. Studying the motivational sphere of students with different types of personality and character. University Management, 2011, No 6

Polozov A.A. Psychological portraits of the sports club staff // Sports psychologist, No 3 (6), 2005.

Polozov A.A. [and others] Age peaks of the career of a sports judge and coach / Theory and practice of physical culture. $\neg$ 2016. $\neg$ No. 1. $\neg$ P. 80: ill. Bibliography: p. 80 (3 titles). $\neg$ ISSN 0040 $73601 \mathrm{UDC}^{\wedge}$ a796.01 BBK 75.

Career center https://cms.bsu.edu/about/administrativeoffices/careercenter/toolsresources/personality-types/esfp

Career center https://study.com/articles/ jobs_for_people_with_isfp.html

Career center http://www.truity.com/content

Career center https://www.indeed.com

Career center https://www.ziprecruiter.com/

Career center Ball State University

Career center https://www.talentdesk.com

Career center https://www.depressionalliance.org

Career center The Myers-Briggs Foundation Web Site.

Career center http://www.skolkovo.ru/public/ru/research/sedec/sedec-actual/sedec-asi/

Shmelev A.G., Serebryakov A.G. Psychodiagnostics in vocational guidance: principles of infrastructural support of computerized testing // Psychological diagnostics. 2006. No 2. - p. 4-16.

Shmelev A.G. It's not socionics, but differential psychology. // Vestnik SUSU. Series: Psychology. - 2010. - No. 27 (203). - P. 10

Page, Earle C. Looking at Type: A Description of the Preferences Reported by the MyersBriggs Type Indicator. Center for Applications of Psychological Type.

Tieger, Paul D., Barron, Barbara, and Tieger, Kelly. Do What You Are. NY: Hatchette Book Group (2014)

Barbara Barron, Paul Tieger «Do What You Are: Discover the Perfect Career for You Through the Secrets of Personality Type» : 
Excerpts from Do What You Are by Paul D. Tieger and Barbara Barron Fourth Edition: March 2007

Baron, Renee. (1998) What Type Am I?. NY: Penguin Books.

Sipps, G.J., R.A. Alexander, and L. Friedt. «Item Analysis of the Myers-Briggs Type Indicator.»Educational and Psychological Measurement, Vol. 45, No. 4 (1985), pp. $789-796$.

Jones B., Reedy E.J., Weinberg B. A. / Age and Scientific Genius. NBER Working Paper No. 19866 Issued in January 2014 NBER

McCrae, R.R. and P.T. Costa. «Reinterpreting the Myers-Briggs Type Indicator from the Perspective of the Five-Factor Model of Personality.» Journal of Personality, Vol. 57, No. 1 (1989), pp. 12-40.

David J. Pittenger. «Measuring the MBTI... and Coming Up Short». Journal of Career Planning \& Placement (autumn, 1993).

Myers-Briggs Widely Used But Still Controversial

Druckman, D. and Bjork, R. A. Eds. In the Mind's Eye: Enhancing Human Performance. Washington, DC: National Academy Press, 1991.

McCrae R.R., Costa P.T. (1989) Reinterpreting the Myers-Briggs Type Indicator From the Perspective of the Five-Factor Model of Personality. Journal of Personality. vol. 57 p. 17-40 pmid $=2709300 \mathrm{doi}=10.1111 / \mathrm{j} .1467-6494.1989 . t b 00759 . \mathrm{x}$

Stricker, L J; Ross, J (1964). «An Assessment of Some Structural Properties of the Jungian Personality Typology». Journal of Abnormal and Social Psychology 68: 62-71. 